\title{
Interactions of miR-34b/c and TP53 Polymorphisms on the Risk of Intracranial Aneurysm
}

\author{
Lijuan Li, ${ }^{1,2}$ Xiutian Sima, ${ }^{3}$ Peng Bai, ${ }^{2}$ Lushun Zhang, ${ }^{2}$ Hong Sun, ${ }^{1}$ Weibo Liang, ${ }^{2}$ \\ Jianxing Liu, ${ }^{4}$ Lin Zhang, ${ }^{1,2,5}$ and Linbo Gao ${ }^{1,5}$ \\ ${ }^{1}$ Laboratory of Molecular and Translational Medicine, West China Institute of Women and Children's Health, \\ West China Second University Hospital, Sichuan University, Chengdu 610041, China \\ ${ }^{2}$ Department of Forensic Biology, West China School of Preclinical and Forensic Medicine, Sichuan University, Chengdu 610041, China \\ ${ }^{3}$ Department of Neurosurgery, West China Hospital, Sichuan University, Chengdu 610041, China \\ ${ }^{4}$ Department of Forensic Medicine, Kunming Medical University, Kunming 650031, China \\ ${ }^{5}$ Key Laboratory of Obstetric \& Gynecologic and Pediatric Diseases and Birth Defects of Ministry of Education, \\ Chengdu, Sichuan 610041, China
}

Correspondence should be addressed to Lin Zhang, zhanglin@scu.edu.cn and Linbo Gao, cdchglb@gmail.com

Received 10 April 2012; Accepted 22 May 2012

Academic Editor: G. Opdenakker

Copyright ( $) 2012$ Lijuan Li et al. This is an open access article distributed under the Creative Commons Attribution License, which permits unrestricted use, distribution, and reproduction in any medium, provided the original work is properly cited.

\begin{abstract}
Several lines of evidence indicate that inflammatory processes play a key role in the happening and development of intracranial aneurysm (IA). Recently, polymorphisms in the TP53 gene were shown to be associated with inflammation and inflammatory disease. The aim of this study was to investigate the interactions of $m i R-34 b / c$ and TP53 Arg72-Pro polymorphisms on the risk of IA in a Chinese population. A total of 590 individuals (including 164 patients with IA and 426 controls) were involved in this study. The polymorphisms (i.e., miR-34b/c rs4938723 and TP53 Arg72-Pro) were genotyped by polymerase chain reactionrestriction fragment length polymorphism assay and DNA sequencing. We found that the CC genotype of $m i R-34 b / c$ rs4938723 was significantly associated with a decreased risk of IA compared with the TT genotype. Moreover, a significant gene interaction of the carriers with the combined genotypes of $m i R-34 b / c$ rs4938723CC and TP53 Arg72Pro CG/CC/GG had a decreased risk of IA, compared with those carrying miR-34b/c rs4938723CT/TT+TP53 Arg72Pro GG/CG/CC combined genotypes. These findings suggest that the miR-34b/c rs4938723CC and TP53 Arg72-Pro polymorphisms may be involved in the susceptibility to IA.
\end{abstract}

\section{Introduction}

Intracranial aneurysm (IA) is a common disease with a high prevalence ranging from 1 to 5 percent in large autopsy studies [1]. Rupture of IAs causes approximately $75 \%$ of all subarachnoid hemorrhage $(\mathrm{SAH})$ cases and most ruptured IAs present with SAH [2-7]. SAH remains a critical condition, with only $25 \%$ of victims living independently [8]. Inflammation was firstly suggested to occur in IAs by Virchow in 1847 [9], and further evidence came from the 1930s when Maass [10,11] described round cell infiltration, most likely lymphocytes that have been regularly detected in immunohistochemical studies of the IA wall [12-14] are associated with IA rupture $[15,16]$. In experimental IA in rodents, macrophage infiltration goes after IA formation and endothelial dysfunction $[17,18]$. The role of inflammation in the formation and progression of aneurysm has not been well investigated, but there was considerable circumstantial evidence linking inflammation to IA [12, 19-21].

Both environmental and genetic factors are involved in the etiology of IA $[22,23]$. Several studies have revealed candidate genes in different populations [24-34]. Indeed, there is a three- to fivefold increased risk for first-degree relatives of affected individuals, compared with the general population $[35,36]$. The TP53 gene has an important function in cell cycle control, apoptosis, and maintenance of DNA integrity [37-39]. The importance of p53 in cell cycle regulation and DNA integrity is such that it has been called the "guardian of the genome" [40]. TP53, located on chromosome 17p13 $[41,42]$ is $19 \mathrm{~kb}$ in size and consists of 11 exons resulting in a 
transcript of $2629 \mathrm{bp}$ and a protein of 393 amino acids [43]. Codon 72 (Arg72Pro) in exon 4 of the TP53 gene is a frequent functional SNP that leads to a methionine proline conversion $[44,45]$. The TP53 Arg72Pro SNP results in a change in its protein structure reflected by its altered electrophoretic mobility [46], and this SNP exists only in humans [45]. More importantly, the Arg72Pro polymorphism of TP53 was reported to influence the p53-mediated inflammatory response [47].

It is well known that p53 can regulate the expression of miRNAs, especially the miR-34 family members, which compose 3 mature miRNAs that are encoded by 2 different pri-miRNAs [48-54]. The promoter regions of both transcripts contain p53-binding sites [49]. A potentially functional common SNP rs4938723 ( $\mathrm{T}>\mathrm{C}$ ) has been found in the promoter region of $m i R-34 \mathrm{~b} / \mathrm{c}$, which may contribute to the susceptibility of HCC in a Chinese population [21].

In this study, we hypothesized that SNPs rs4938723 $(\mathrm{T}>\mathrm{C})$ in the promoter region of $m i R-34 \mathrm{~b} / \mathrm{c}$ and TP53 Arg72-Pro were associated with the risk of IA. To test this hypothesis, we genotyped the 2 SNPs in a case-control study of 164 IA patients and 426 healthy controls in a Chinese population.

\section{Subjects and Methods}

2.1. Study Populations. The study was performed with the approval of the hospital ethics committee, and written informed consent was obtained from all subjects participating in this study. The case-control study population contained 590 unrelated Chinese Han individuals including 164 patients (60 males and 104 females, mean age: 53.1 $( \pm 13.1)$ ) with IA and 426 healthy controls (205 males and 221 females, mean age: $51.3( \pm 8.9))$ living in Sichuan province of southwest China. Patients were recruited from the West China Hospital, Sichuan University from January 2008 to September 2009 who were newly diagnosed when they came for emergency because of SAH caused by the rupture of IA or just had general clinical symptoms such as headache or dizziness and diagnosed by DSA (digital subtraction angiography). The control group consisted of 426 healthy volunteers from a routine health survey in the same hospital during the same time as the patients. Subjects with any disease in nervous system or other serious illness were intentionally excluded. There was no significant difference between patients and control subjects in age distribution.

2.2. Genotyping. Genomic DNA was extracted from $200 \mu \mathrm{L}$ EDTA-anticoagulated peripheral blood using a commercial extraction kit (Bioteke Corporation, Beijing, China) according to the instruction manual. We used a polymerase chain reaction-restriction fragment length polymorphism assay to detect the genotype of the two SNPs (i.e., $m i R$ 34b/c rs4938723 and TP-53 Arg72-Pro). Primer sequences, reaction conditions, restriction enzymes ( $\mathrm{New}$ England BioLabs Inc; Beverly, MA, USA) used, and length of resulting polymerase chain reaction products have been described previously [21]. Restriction fragments were distinguished on $6 \%$ polyacrylamide gel and stained with $1.0 \mathrm{~g} / \mathrm{L}$ argent nitrate to determine the genotypes. The PCR products of the two SNPs with different genotypes were randomly selected to be confirmed by DNA sequencing, and the results were $100 \%$ consistent.

2.3. Statistical Analysis. In this retrospective study, demographic and clinical data of both groups were compared by the chi-square test and $t$ test. Genotype and allele frequencies of $m i R-34 b / c$ rs4938723 and TP53 Arg72Pro were obtained using Modified-Powerstates standard edition software. Hardy-Weinberg equilibrium was tested with chisquare test to compare the observed genotype frequencies among the subjects with the expected genotype frequencies. Genotype and allele frequencies of the two SNPs were compared between IA cases and controls using the chi-square tests. Odds ratios (ORs) and 95\% confidence intervals (CIs) were used to assess the relative risk conferred by a particular allele, genotype, or the combined genotypes of $m i R-34 b / c$ rs4938723 and TP53 Arg72Pro. Statistical significance was set at the $P<0.05$ level. All the data were analyzed using the SPSS for windows software package version 13.0 (SPSS Inc., Chicago, IL).

\section{Results}

The two SNPs of $m i R-34 b / c$ rs4938723 and TP53 Arg72Pro were successfully genotyped for 164 patients with IA and 426 controls. The clinical characteristics including sex, age of both groups, and the number of aneurysms in the cases enrolled in our study are shown in Table 1. The mean age of all subjects was almost identical. There were more females among the cases (63.4\%) than those in the controls $(51.9 \%)$. The genotype and allele frequencies distribution of both polymorphisms in the control group met the requirements of the Hardy-Weinberg equilibrium. The genotype and allele frequencies of the two SNPs and the combined genotypes frequencies of $m i R-34 b / c$ rs4938723 and TP53 Arg72Pro are summarized in Tables 2, 3 and 4. The CC genotype of $m i R-34 b / c$ rs4938723 was significantly associated with a decreased risk of IA, compared with the TT genotype $(\mathrm{OR}=0.28,95 \% \mathrm{CI}: 0.11-0.73, P=$ 0.006). However, no association between TP53 Arg72Pro and the risk of IA was observed for genotypic or allelic association analysis. We also examined the combined effects of $m i R-34 b / c$ rs 4938723 and TP53 Arg72Pro variants on IA risk. As shown in Table 3, the carriers with the combined genotypes of rs4938723CC and TP53 Arg72Pro CG/CC/GG had a 0.27 -fold decreased risk of IA (OR $=0.27,95 \%$ CI: $0.11-0.70, P=0.004)$, compared with those carrying rs4938723CT/TT + TP53 Arg72Pro CG/CC/GG combined genotypes, while no other association between combined effects of $m i R-34 b / c$ rs4938723 and TP53 Arg72Pro variants on IA risk was found. When stratification analysis was done by gender, no association was found (Tables 5 and 6). No significant association between the two SNPs and the number of aneurysms was observed (Table 7). 
TABLE 1: Demographics of the patients with intracranial aneurysm and controls.

\begin{tabular}{lcc}
\hline Variables & Controls $n=426(\%)$ & Patients with intracranial aneurysm $n=164(\%)$ \\
\hline Age $(\mathrm{y})$ & $51.3( \pm 8.9)$ & $53.1( \pm 13.1)$ \\
Sex & $205(48.1)$ & $60(36.6)$ \\
$\quad$ Male & $221(51.9)$ & $104(63.4)$ \\
$\quad$ Female & - & 142 \\
Number of aneurysms & - & 22 \\
$\quad 1$ & &
\end{tabular}

TABLE 2: Genotype frequencies of miR-34 rs4938723 and TP-53 Arg72Pro between patients with intracranial aneurysm and controls.

\begin{tabular}{lccc}
\hline Polymorphisms & Controls $n=426(\%)$ & Patients $n=164(\%)$ & OR (95\% CI) \\
\hline rs4938723 & $188(44.1)$ & $77(47.0)$ & $1.0($ ref $)$ \\
TT & $194(45.6)$ & $82(50.0)$ & $1.03(0.71-1.49)$ \\
CT & $44(10.3)$ & $5(3.0)$ & $0.28(0.11-0.73)$ \\
CC & & & 0.87 \\
TP-53 & $145(34.0)$ & $60(36.6)$ & $1.0($ ref $)$ \\
GG & $223(52.4)$ & $77(46.9)$ & $0.83(0.56-1.24)$ \\
CG & $58(13.6)$ & $27(16.5)$ & $1.13(0.65-1.94)$ \\
CC & & & 0.37 \\
\hline
\end{tabular}

OR: odds ratio.

CI: confidence interval.

Ref: reference.

TABLE 3: The combined genotypes frequencies of miR-34 rs4938723 and TP-53 Arg72Pro between patients with intracranial aneurysm and controls.

\begin{tabular}{lccc}
\hline Polymorphisms & Controls $n(\%)$ & Patients $n(\%)$ & OR (95\% CI) \\
\hline rs4938723CT/TT + TP53CG/CC & $255(66.8)$ & $100(62.9)$ & $1.0($ ref $)$ \\
rs4938723CT/TT + TP53GG & $127(33.2)$ & $59(37.1)$ & $1.19(0.81-1.74)$ \\
rs4938723CT/TT + TP-53 CG/CC/GG & $382(89.7)$ & $159(97.0)$ & $1.0($ ref $)$ \\
rs4938723CC + TP-53 CG/CC/GG & $44(10.3)$ & $5(3.0)$ & $0.27(0.11-0.70)$ \\
\hline
\end{tabular}

OR: odds ratio.

CI: confidence interval.

Ref: reference.

TABLE 4: Allele frequencies of miR-34 rs4938723 and TP-53 Arg72Pro between patients with intracranial aneurysm and controls.

\begin{tabular}{cccc}
\hline Alleles & Controls $n=426(\%)$ & Patients $n=164(\%)$ & OR (95\% CI) \\
\hline rs4938723 & $570(66.9)$ & $236(72.0)$ & $1.0($ ref $)$ \\
T & $282(33.1)$ & $92(28.0)$ & $0.79(0.60-1.04)$ \\
C & & & 0.10 \\
TP-53 & $513(60.2)$ & $197(60.1)$ & $1.0($ ref $)$ \\
G & $339(39.8)$ & $131(39.9)$ & $1.01(0.78-1.31)$ \\
C & & & 0.96 \\
\hline
\end{tabular}

OR: odds ratio.

CI: confidence interval.

Ref: reference. 
TABLE 5: Genotype frequencies of miR-34 rs4938723 and TP-53 Arg72Pro in female subjects.

\begin{tabular}{lccc}
\hline Polymorphisms & Controls $n=221(\%)$ & Patients $n=104(\%)$ & OR (95\% CI $)$ \\
\hline rs4938723 & $96(43.4)$ & $42(40.4)$ & $1.0($ ref $)$ \\
TT & $103(46.6)$ & $59(56.7)$ & $1.31(0.81-2.12)$ \\
CT & $125(56.6)$ & $62(59.6)$ & $1.13(0.71-1.82)$ \\
CC/CT & & & 0.27 \\
TP-53 & $74(33.5)$ & $39(37.5)$ & 0.60 \\
GG & $117(52.9)$ & $47(45.2)$ & $0.76(0.46-1.28)$ \\
CG & $30(13.6)$ & $18(17.3)$ & $1.14(0.57-2.30)$ \\
CC & & & 0.30 \\
\hline
\end{tabular}

OR: odds ratio.

CI: confidence interval.

Ref: reference.

TABLe 6: Genotype frequencies of miR-34 rs4938723 and TP-53 Arg72Pro in male subjects.

\begin{tabular}{lccc}
\hline Polymorphisms & Controls $n=205(\%)$ & Patients $n=60(\%)$ & OR (95\% CI) \\
\hline rs4938723 & $92(44.9)$ & $35(58.3)$ & $1.0($ ref $)$ \\
TT & $91(44.4)$ & $23(38.3)$ & $0.66(0.36-1.21)$ \\
CT & $113(55.1)$ & $25(41.7)$ & $0.58(0.33-1.04)$ \\
CC/CT & & & 0.18 \\
TP-53 & $71(34.6)$ & $21(35.0)$ & 0.07 \\
GG & $106(51.7)$ & $30(50.0)$ & $0.96(0.51-1.80)$ \\
CG & $28(13.7)$ & $9(15.0)$ & $1.09(0.44-2.66)$ \\
CC & & & 0.89 \\
\hline
\end{tabular}

OR: odds ratio.

CI: confidence interval.

Ref: reference.

\section{Discussion}

In this study, we investigated the association between two SNPs (i.e., $m i R-34 b / c$ rs4938723 and TP53 Arg72Pro) and the risk of IA in a Chinese population. We found that the CC genotype of $m i R-34 \mathrm{~b} / \mathrm{c}$ rs4938723 was significantly associated with a decreased risk of IA, compared with the TT genotype. Moreover, a gene interaction of the carriers with the combined genotypes of $m i R-34 b / c$ rs4938723CC and TP53 Arg72Pro CG/CC/GG had a decreased risk of IA, compared with those carrying $m i R-34 b / c$ rs4938723 CT/TT + TP53 Arg72Pro CG/CC/GG combined genotypes. However, no difference was found when stratification analysis was done by gender for both $m i R-34 b / c$ rs4938723CC and TP53 Arg72Pro.

There are two $m i R-34$ loci in vertebrate genomes, one encoding $m i R-34 a$ and the other generating both $m i R$ $34 b$ and $m i R-34 c$. Both genes show little conservation even among closely related species, except in the miRNA-encoding sequences and in short promoter proximal regions that each contains a consensus p53-binding site [48-54]. Polymorphisms in miRNA genes may alter miRNA processing by changing the stem-loop structure. Although this is not an active processing regulation mechanism, it is evident that SNPs do alter the processing efficiency [55]. Several candidate genes have been analyzed in order to investigate the possible impact of inflammation-associated SNP on the development of IA [56-62]. When it comes to TP53, the inflammatory microenvironment both activates the p53 network and inactivates the tumor suppressor activity by mutation of the p53 gene [63-65]. Another link between p53 and inflammation is suggested by studies demonstrating the presence of TP53 mutations in areas of rheumatoid arthritis (RA) synovial tissues [66-69]. Frank et al. [47] reported that the Arg72Pro polymorphism of TP53 influences the p53-mediated inflammatory response. The role of p53 in innate immunity and the inflammatory response is now well established [70-72] and, importantly, is evolutionarily conserved [73]. Also a rat model experiment indicated that inflammation modulates miRNA expression in vivo and the alteration of $m i R-34 b / c$ under an inflammatory microenvironment can be influenced by p53 [74].

Although the molecular mechanisms by which miRNA and $p 53$ gene polymorphisms are associated with IA remain unclear, additional functional studies would provide valuable characterization of the molecular mechanisms by which miRNA and TP53 are involved in susceptibility to IA. However, our study provides evidence that miRNA and TP53 polymorphisms may play an important role in individuals' susceptibility to IA.

There were several limitations in our study. Firstly, detailed lifestyle that may be involved in the occurrence and development of IA was not available. Secondly, the number of subjects in the study was so small which might not be a good representative of the general population. Further studies, therefore, still need to be done. 
TABLE 7: Stratified analysis by the number of aneurysms.

\begin{tabular}{lccc}
\hline Polymorphisms & \multicolumn{2}{c}{ The number of aneurysms } & OR $(95 \%$ CI $)$ \\
& $n=142$ & $n=22$ & \\
\hline rs4938723 & & & $1.0($ ref $)$ \\
TT & $64(45.1)$ & $9(40.9)$ & $0.57(0.23-1.41)$ \\
CT/CC & $78(54.9)$ & & $1.0($ ref $)$ \\
TP-53 & $53(37.3)$ & $7(31.8)$ & $1.28(0.49-3.33)$ \\
GG & $89(62.7)$ & $15(68.2)$ & 0.22 \\
CG/CC & & & 0.62 \\
\hline
\end{tabular}

OR: odds ratio.

CI: confidence interval.

Ref: reference.

In conclusion, we found that the CC genotype of miR$34 \mathrm{~b} / \mathrm{c} \mathrm{rs} 4938723$ was significantly associated with a decreased risk of IA, and a significant gene interaction of $m i R$ 34b/c rs4938723CT/TT and TP53 Arg72Pro CG/CC/GG was evident on the risk of IA. These findings suggest that $m i R$ $34 b / c$ rs4938723 and TP53 Arg72Pro play a role in the formation, process, or rupture of IA. Nevertheless, our findings need to be replicated in larger, preferably multiethic population-based studies.

\section{Conflict of Interests}

None of the authors has any potential financial conflict of interests related to this paper.

\section{Acknowledgments}

This work was supported by the special research foundation of doctoral priority to the development of field project (No. 20110181130013) and the Program for Changjiang Scholars and Innovative Research Team in University (IRT 0935).

\section{References}

[1] D. O. Wiebers, J. P. Whisnant, J. Huston 3rd et al., "Unruptured intracranial aneurysms: natural history, clinical outcome, and risks of surgical and endovascular treatment," The Lancet, vol. 362, pp. 103-110, 2003.

[2] B. Weir, "Unruptured intracranial aneurysms: a review," Journal of Neurosurgery, vol. 96, no. 1, pp. 3-42, 2002.

[3] S. Pakarinen, "Incidence, aetiology, and prognosis of primary subarachnoid haemorrhage. A study based on 589 cases diagnosed in a defined urban population during a defined period," Acta Neurologica Scandinavica, vol. 43, supplement 29, pp. 1-8, 1967.

[4] G. J. E. Rinkel, M. Djibuti, A. Algra, and J. van Gijn, "Prevalence and risk of rupture of intracranial aneurysms: a systematic review," Stroke, vol. 29, no. 1, pp. 251-256, 1998.

[5] J. van Gijn and G. J. E. Rinkel, "Subarachnoid haemorrhage: diagnosis, causes and management," Brain, vol. 124, no. 2, pp. 249-278, 2001.

[6] W. I. Schievink, "Genetics of intracranial aneurysms," Neurosurgery, vol. 40, no. 4, pp. 651-663, 1997.
[7] A. Ronkainen, J. Hernesniemi, M. Puranen et al., "Familial intracranial aneurysms," The Lancet, vol. 349, no. 9049, pp. 380-384, 1997.

[8] C. Pritchard, L. Foulkes, D. A. Lang, and G. Neil-Dwyer, "Psychosocial outcomes for patients and carers after aneurysmal subarachnoid haemorrhage," British Journal of Neurosurgery, vol. 15, no. 6, pp. 456-463, 2001.

[9] R. Virchow, "Uber die akute Entzundung der Arterien," Virchows Arch A Pathol Anat Histopathol, vol. 1, pp. 272-378, 1847.

[10] U. Maass, "Die syphilis als ha üfigste ursache der aneurysmen an der gehirnbasis," Beiträge zur Pathologischen Anatomie und zur Allgemeinen Pathologie, vol. 98, pp. 307-322, 1937.

[11] O. Hassler, "Morphological studies on the large cerebral arteries, with reference to the aetiology of subarachnoid haemorrhage," Acta Psychiatrica Scandinavica, vol. 154, pp. 1$145,1961$.

[12] D. Chyatte, G. Bruno, S. Desai, and D. R. Todor, "Inflammation and intracranial aneurysms," Neurosurgery, vol. 45, no. 5, pp. 1137-1147, 1999.

[13] M. Holling, A. Jeibmann, J. Gerss et al., "Prognostic value of histopathological findings in aneurysmal subarachnoid hemorrhage," Journal of Neurosurgery, vol. 110, no. 3, pp. 487491, 2009.

[14] T. A. Kosierkiewicz, S. M. Factor, and D. W. Dickson, "Immunocytochemical studies of atherosclerotic lesions of cerebral berry aneurysms," Journal of Neuropathology and Experimental Neurology, vol. 53, no. 4, pp. 399-406, 1994.

[15] K. Kataoka, M. Taneda, T. Asai, A. Kinoshita, M. Ito, and R. Kuroda, "Structural fragility and inflammatory response of ruptured cerebral aneurysms: a comparative study between ruptured and unruptured cerebral aneurysms," Stroke, vol. 30, no. 7, pp. 1396-1401, 1999.

[16] J. Frosen, A. Piippo, A. Paetau et al., "Remodeling of saccular cerebral artery aneurysm wall is associated with rupturehistological analysis of 24 unruptured and 42 ruptured cases," Stroke, vol. 35, pp. 2287-2293, 2004.

[17] M. A. Jamous, S. Nagahiro, K. T. Kitazato et al., "Endothelial injury and inflammatory response induced by hemodynamic changes preceding intracranial aneurysm formation: experimental study in rats," Journal of Neurosurgery, vol. 107, no. 2, pp. 405-411, 2007.

[18] T. Aoki, H. Kataoka, M. Morimoto, K. Nozaki, and N. Hashimoto, "Macrophage-derived matrix metalloproteinase2 and -9 promote the progression of cerebral aneurysms in rats," Stroke, vol. 38, no. 1, pp. 162-169, 2007. 
[19] F. P. Handler and H. T. Blumenthal, "Inflammatory factor in pathogenesis of cerebrovascular aneurysms," Journal of the American Medical Association, vol. 155, no. 17, pp. 1479-1483, 1954.

[20] T. Jayaraman, V. Berenstein, X. G. Li et al., "Tumor necrosis factor $\alpha$ is a key modulator of inflammation in cerebral aneurysms," Neurosurgery, vol. 57, no. 3, pp. 558-563, 2005.

[21] Y. Xu, L. Liu, J. Liu et al., "A potentially functional polymorphism in the promoter region of $m i R-34 b / c$ is associated with an increased risk for primary hepatocellular carcinoma," International Journal of Cancer, vol. 128, no. 2, pp. 412-417, 2011.

[22] W. I. Schievink, D. J. Schaid, V. V. Michels, and D. G. Piepgras, "Familial aneurysmal subarachnoid hemorrhage: a community-based study," Journal of Neurosurgery, vol. 83, no. 3, pp. 426-429, 1995.

[23] A. Ronkainen, H. Miettinen, K. Karkola et al., "Risk of harboring an unruptured intracranial aneurysm," Stroke, vol. 29, no. 2, pp. 359-362, 1998.

[24] B. V. Nahed, A. Seker, B. Guclu et al., "Mapping a Mendelian form of intracranial aneurysm to 1p34.3-p36.13," American Journal of Human Genetics, vol. 76, no. 1, pp. 172-179, 2005.

[25] J. M. Olson, S. Vongpunsawad, H. Kuivaniemi et al., "Search for intracranial aneurysm susceptibility gene(s) using Finnish families," BMC Medical Genetics, vol. 3, article 7, 2002.

[26] H. Onda, H. Kasuya, T. Yoneyama et al., "Genomewidelinkage and haplotype-association studies map intracranial aneurysm to chromosome 7q11," American Journal of Human Genetics, vol. 69, no. 4, pp. 804-819, 2001.

[27] A. K. Ozturk, B. V. Nahed, M. Bydon et al., "Molecular genetic analysis of two large kindreds with intracranial aneurysms demonstrates linkage to 11q24-25 and 14q23-31," Stroke, vol. 37, no. 4, pp. 1021-1027, 2006.

[28] D. J. Verlaan, M. P. Dubé, J. St-Onge et al., "A new locus for autosomal dominant intracranial aneurysm, ANIB4, maps to chromosome 5p15.2-14.3," Journal of Medical Genetics, vol. 43, no. 6 , p. e31, 2006.

[29] H. Onda, T. Yoneyama, H. Akagawa, and H. Kasuya, "Genetic dissection of intracranial aneurysm," Brain and Nerve, vol. 60, no. 11, pp. 1245-1260, 2008.

[30] B. Krischek and I. Inoue, "The genetics of intracranial aneurysms," The American Journal of Human Genetics, vol. 51, pp. 587-594, 2006.

[31] B. V. Nahed, M. Bydon, A. K. Ozturk, K. Bilguvar, F. Bayrakli, and M. Gunel, "Genetics of intracranial aneurysms," Neurosurgery, vol. 60, no. 2, pp. 213-225, 2007.

[32] Y. M. Ruigrok and G. J. E. Rinkel, "Genetics of intracranial aneurysms," Stroke, vol. 39, no. 3, pp. 1049-1055, 2008.

[33] S. Weinsheimer, G. M. Lenk, M. van der Voet et al., "Integration of expression profiles and genetic mapping data to identify candidate genes in intracranial aneurysm," Physiological Genomics, vol. 32, no. 1, pp. 45-57, 2007.

[34] M. van der Voet, J. M. Olson, H. Kuivaniemi et al., "Intracranial aneurysms in Finnish families: confirmation of linkage and refinement of the interval to chromosome 19q13.3," American Journal of Human Genetics, vol. 74, no. 3, pp. 564$571,2004$.

[35] W. E. Stehbens and W. I. Schievink, "Familial intracranial aneurysms: an autopsy study," Neurosurgery, vol. 43, no. 5, pp. 1258-1259, 1998.

[36] A. Ronkainen, M. Niskanen, R. Piironen, and J. Hernesniemi, "Familial subarachnoid hemorrhage: outcome study," Stroke, vol. 30, no. 5, pp. 1099-1102, 1999.
[37] A. J. Levine, "p53, the cellular gatekeeper for growth and division," Cell, vol. 88, no. 3, pp. 323-331, 1997.

[38] R. Sager, "Tumor suppressor genes: the puzzle and the promise," Science, vol. 246, no. 4936, pp. 1406-1412, 1989.

[39] H. Xu and M. R. El-Gewely, "P53-responsive genes and the potential for cancer diagnostics and therapeutics development," Biotechnology Annual Review, vol. 7, pp. 131-164, 2001.

[40] D. P. Lane, "p53, guardian of the genome," Nature, vol. 358, no. 6381, pp. 15-16, 1992.

[41] B. Iacopetta, "TP53 mutation in colorectal cancer," Human Mutation, vol. 21, no. 3, pp. 271-276, 2003.

[42] C. Whibley, P. D. P. Pharoah, and M. Hollstein, "p53 polymorphisms: cancer implications," Nature Reviews Cancer, vol. 9, no. 2, pp. 95-107, 2009.

[43] S. E. Bojesen and B. G. Nordestgaard, "The common germline Arg72Pro polymorphism of p53 and increased longevity in humans," Cell Cycle, vol. 7, no. 2, pp. 158-163, 2008.

[44] M. Thomas, A. Kalita, S. Labrecque, D. Pim, L. Banks, and G. Matlashewski, "Two polymorphic variants of wild-type p53 differ biochemically and biologically," Molecular and Cellular Biology, vol. 19, no. 2, pp. 1092-1100, 1999.

[45] P. Dumont, J. I. J. Leu, A. C. Della Pietra, D. L. George, and M. Murphy, "The codon 72 polymorphic variants of p53 have markedly different apoptotic potential," Nature Genetics, vol. 33, no. 3, pp. 357-365, 2003.

[46] G. J. Matlashewski, S. Tuck, D. Pim, P. Lamb, J. Schneider, and L. V. Crawford, "Primary structure polymorphism at amino acid residue 72 of human p53," Molecular and Cellular Biology, vol. 7, no. 2, pp. 961-963, 1987.

[47] A. K. Frank, J. I. J. Leu, Y. Zhou et al., "The codon 72 polymorphism of p53 regulates interaction with NF$\kappa \mathrm{B}$ and transactivation of genes involved in immunity and inflammation," Molecular and Cellular Biology, vol. 31, no. 6, pp. 1201-1213, 2011.

[48] G. T. Bommer, I. Gerin, Y. Feng et al., "p53-mediated activation of miRNA34 candidate tumor-suppressor genes," Current Biology, vol. 17, no. 15, pp. 1298-1307, 2007.

[49] L. He, X. He, L. P. Lim et al., "A microRNA component of the p53 tumour suppressor network," Nature, vol. 447, no. 7148, pp. 1130-1134, 2007.

[50] T. C. Chang, E. A. Wentzel, O. A. Kent et al., "Transactivation of miR-34a by p53 broadly influences gene expression and promotes apoptosis," Molecular Cell, vol. 26, no. 5, pp. 745$752,2007$.

[51] N. Raver-Shapira, E. Marciano, E. Meiri et al., "Transcriptional activation of miR-34a contributes to p53-mediated Apoptosis," Molecular Cell, vol. 26, no. 5, pp. 731-743, 2007.

[52] V. Tarasov, P. Jung, B. Verdoodt et al., "Differential regulation of microRNAs by 53 revealed by massively parallel sequencing: $m i R-34 a$ is a p53 target that induces apoptosis and G1arrest," Cell Cycle, vol. 6, no. 13, pp. 1586-1593, 2007.

[53] D. C. Corney, A. Flesken-Nikitin, A. K. Godwin, W. Wang, and A. Y. Nikitin, "MicroRNA-34b and MicroRNA-34c are targets of p53 and cooperate in control of cell proliferation and adhesion-independent growth," Cancer Research, vol. 67, no. 18, pp. 8433-8438, 2007.

[54] L. He, X. He, L. P. Lim et al., "A microRNA component of the p53 tumour suppressor network," Nature, vol. 447, no. 7148, pp. 1130-1134, 2007.

[55] I. Slezak-Prochazka, S. Durmus, B. J. Kroesen, and A. van den Berg, "MicroRNAs, macrocontrol: regulation of miRNA processing," RNA, vol. 16, no. 6, pp. 1087-1095, 2010.

[56] L. Morgan, E. Hawe, J. Palmen, H. Montgomery, S. E. Humphries, and N. Kitchen, "Polymorphism of the heme 
oxygenase-1 gene and cerebral aneurysms," British Journal of Neurosurgery, vol. 19, no. 4, pp. 317-321, 2005.

[57] L. Morgan, J. Cooper, H. Montgomery, N. Kitchen, and S. E. Humphries, "The interleukin-6 gene $-174 \mathrm{G}>\mathrm{C}$ and $-572 \mathrm{G}>\mathrm{C}$ promoter polymorphisms are related to cerebral aneurysms," Journal of Neurology, Neurosurgery and Psychiatry, vol. 77, no. 8, pp. 915-917, 2006.

[58] H. Sun, D. Zhang, and J. Zhao, "The interleukin-6 gene $572 \mathrm{G}>\mathrm{C}$ promoter polymorphism is related to intracranial aneurysms in Chinese Han nationality," Neuroscience Letters, vol. 440, no. 1, pp. 1-3, 2008.

[59] J. Pera, M. Korostynski, T. Krzyszkowski et al., "Gene expression profiles in human ruptured and unruptured intracranial aneurysms: what is the role of inflammation?" Stroke, vol. 41, no. 2, pp. 224-231, 2010.

[60] R. J. Rahme and B. R. Bendok, "A role for inflammation in intracranial aneurysm pathophysiology?" Neurosurgery, vol. 66, no. 6, pp. N14-N15, 2010.

[61] R. Tulamo, J. Frosen, A. Paetau et al., "Lack of complement inhibitors in the outer intracranial artery aneurysm wall associates with complement terminal pathway activation," The American Journal of Pathology, vol. 177, pp. 3224-3232, 2010.

[62] R. Tulamo, J. Frösen, E. Laaksamo, M. Niemelä, A. Laakso, and J. Hernesniemi, "Why does the cerebral artery aneurysm rupture?” Duodecim, vol. 127, no. 3, pp. 244-252, 2011.

[63] S. P. Hussain, L. J. Hofseth, and C. C. Harris, "Radical causes of cancer," Nature Reviews Cancer, vol. 3, no. 4, pp. 276-285, 2003.

[64] L. J. Hofseth, S. P. Hussain, G. N. Wogan, and C. C. Harris, "Nitric oxide in cancer and chemoprevention," Free Radical Biology and Medicine, vol. 34, no. 8, pp. 955-968, 2003.

[65] L. M. Coussens and Z. Werb, "Inflammation and cancer," Nature, vol. 420, no. 6917, pp. 860-867, 2002.

[66] Y. Yamanishi, D. L. Boyle, S. Rosengren, D. R. Green, N. J. Zvaifler, and G. S. Firestein, "Regional analysis of p53 mutations in rheumatoid arthritis synovium," Proceedings of the National Academy of Sciences of the United States of America, vol. 99, no. 15, pp. 10025-10030, 2002.

[67] Y. Yamanishi, D. L. Boyle, M. J. Pinkoski et al., "Regulation of joint destruction and inflammation by p53 in collageninduced arthritis," American Journal of Pathology, vol. 160, no. 1, pp. 123-130, 2002.

[68] L. J. Hofseth, S. Saito, S. P. Hussain et al., "Nitric oxideinduced cellular stress and p53 activation in chronic inflammation," Proceedings of the National Academy of Sciences of the United States of America, vol. 100, no. 1, pp. 143-148, 2003.

[69] S. J. Zheng, S. E. Lamhamedi-Cherradi, P. Wang, L. Xu, and Y. H. Chen, "Tumor suppressor p53 inhibits autoimmune inflammation and macrophage function," Diabetes, vol. 54, no. 5, pp. 1423-1428, 2005.

[70] N. Dharel, N. Kato, R. Muroyama et al., "Potential contribution of tumor suppressor p53 in the host defense against hepatitis C virus," Hepatology, vol. 47, no. 4, pp. 1136-1149, 2008.

[71] C. Munoz-Fontela, S. Macip, L. Martinez-Sobrido et al., "Transcriptional role of p53 in interferon-mediated antiviral immunity," Journal of Experimental Medicine, vol. 205, pp. 1929-1938, 2008.

[72] A. Takaoka, S. Hayakawa, H. Yanai et al., "Integration of interferon- $\alpha / \beta$ signalling to $\mathrm{p} 53$ responses in tumour suppression and antiviral defence," Nature, vol. 424, no. 6948, pp. 516-523, 2003.
[73] L. E. Fuhrman, A. K. Goel, J. Smith, K. V. Shianna, and A. Aballay, "Nucleolar proteins suppress Caenorhabditis elegans innate immunity by inhibiting p53/CEP-1," PLoS Genetics, vol. 5, no. 9, Article ID e1000657, 2009.

[74] E. Mathe, G. H. Nguyen, N. Funamizu et al., "Inflammation regulates microRNA expression in cooperation with p53 and nitric oxide," International Journal of Cancer, vol. 131, no. 3, pp. 760-765, 2012. 


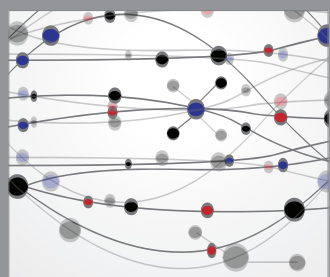

The Scientific World Journal
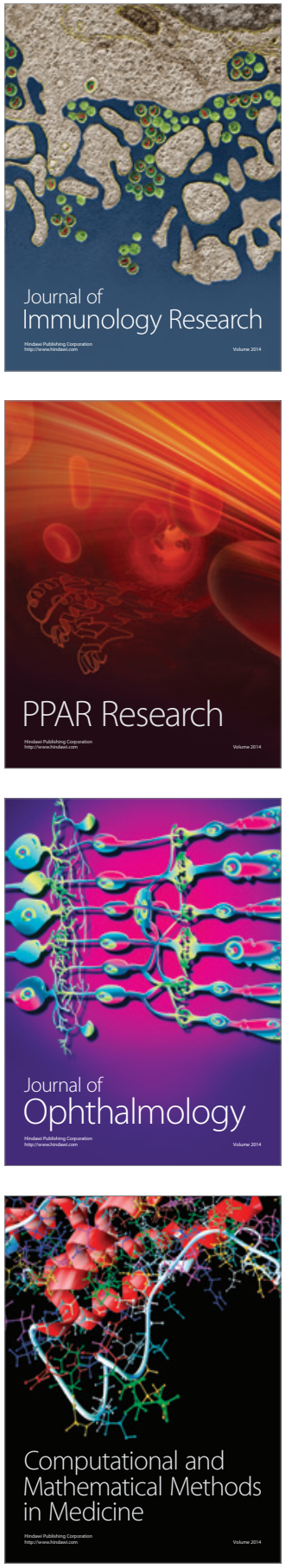

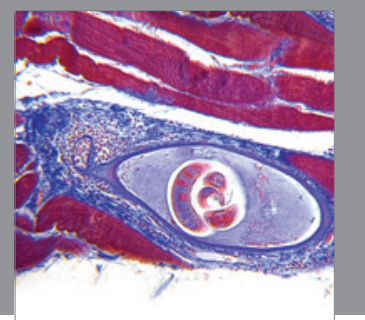

Gastroenterology

Research and Practice
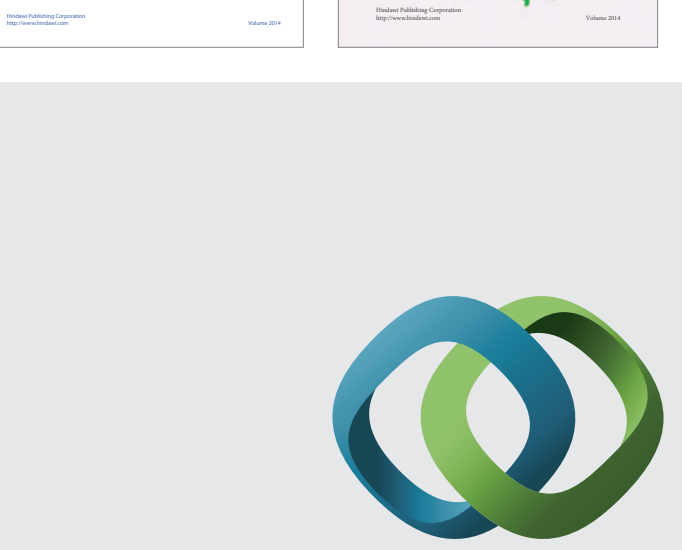

\section{Hindawi}

Submit your manuscripts at

http://www.hindawi.com
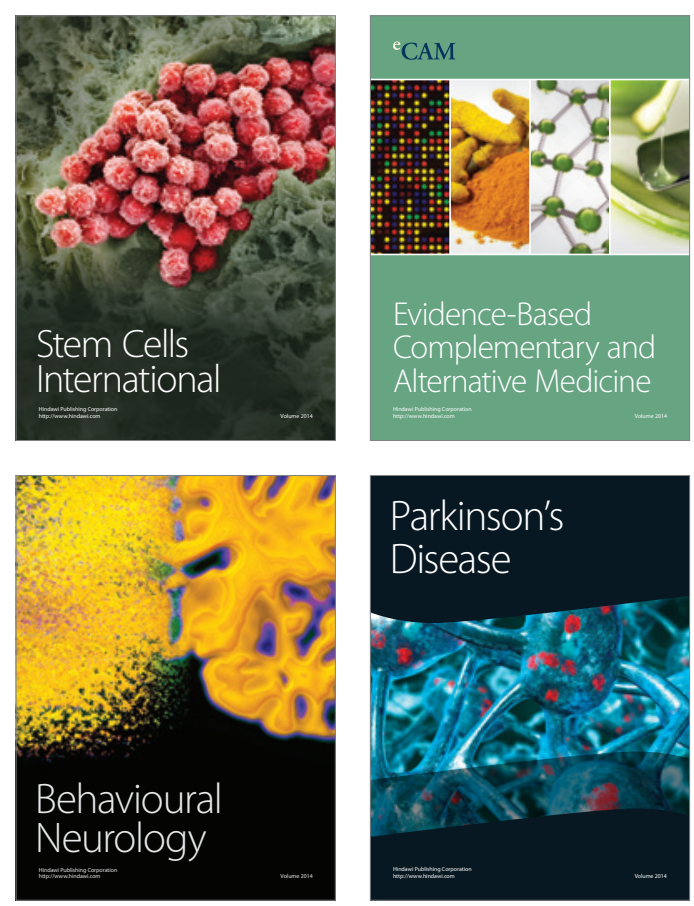

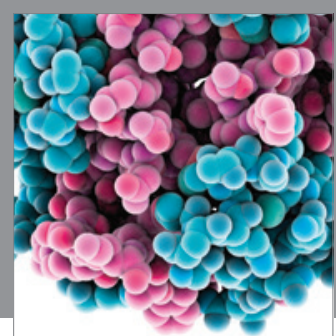

Journal of
Diabetes Research

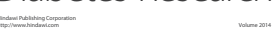

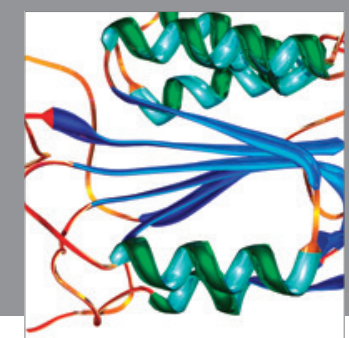

Disease Markers
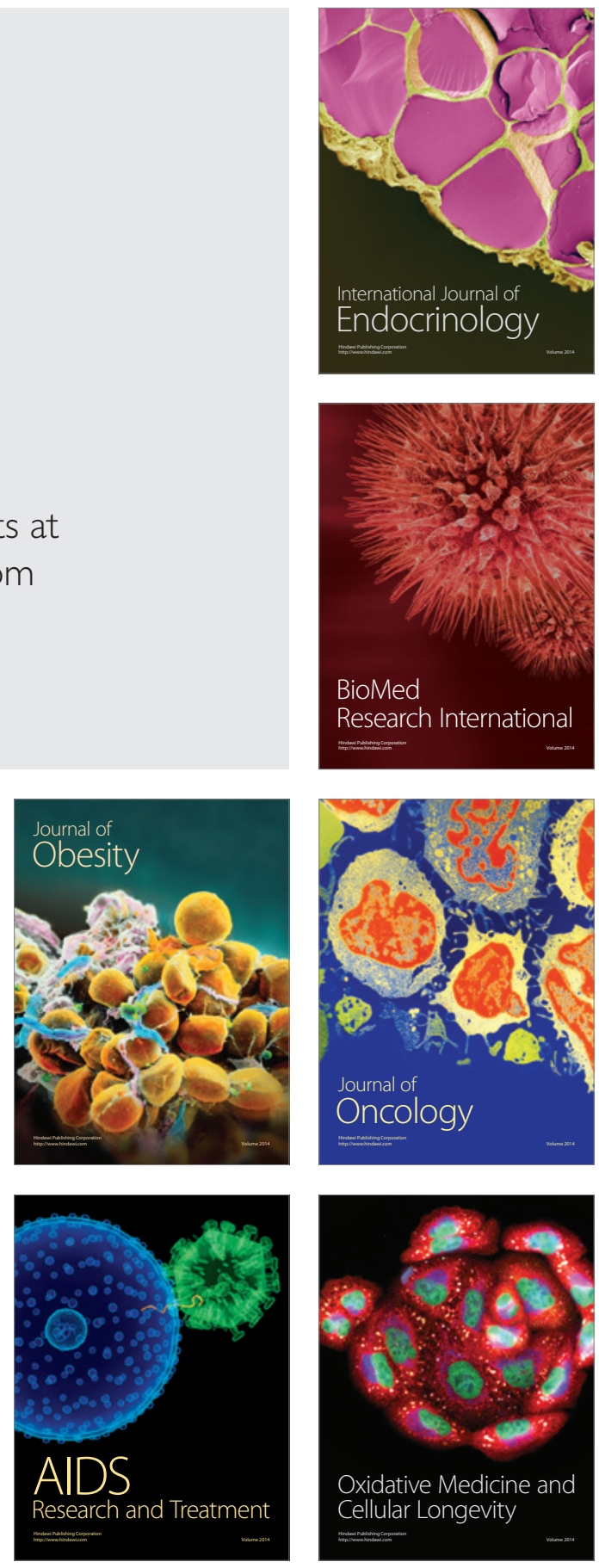